\title{
Learn to save: sustainable schools
}

\author{
A. Boeri \& D. Longo \\ University of Bologna, Department of Architecture and Territorial \\ Planning, Faculty of Architecture "Aldo Rossi", Italy
}

\begin{abstract}
The existing school buildings are mainly characterized by a low level of architectural quality and performance which leads to a high consumption of energy and an indoor microclimate below comfort level.

The design and construction quality of buildings plays a key role in limiting energy consumption, while ensuring proper comfort conditions. Best practice can also effectively encourage experimentations and contribute to formulate sustainable construction strategies that should be widely adopted. School buildings play, in fact, a dual role: on one hand they have to ensure adequate technical and morphological standards to all spaces used by the students; on the other one, they have to effectively communicate the criteria of sustainable design which have been used for their construction.

The aim of attaining higher level of sustainability in the construction sector has led to consider school buildings perfect case studies for testing sustainable technical solutions. This paper proposes some of the most innovative case studies within Italy, highlighting criteria and strategies adopted in the design for spaces dedicated to children. The aim is to promote sustainable design and construction strategies that combine high levels of energy efficiency, of performance standards and environmental indoor quality, including innovative strategies to integrate the building and its related systems.
\end{abstract}

Keywords: energy efficiency, school design, sustainability, innovation, experimentation.

\section{Introduction}

The stock of school buildings represents an extremely important research field for its quantity and social value. The high standards of comfort required by the regulations and innovative research experiences make these buildings 


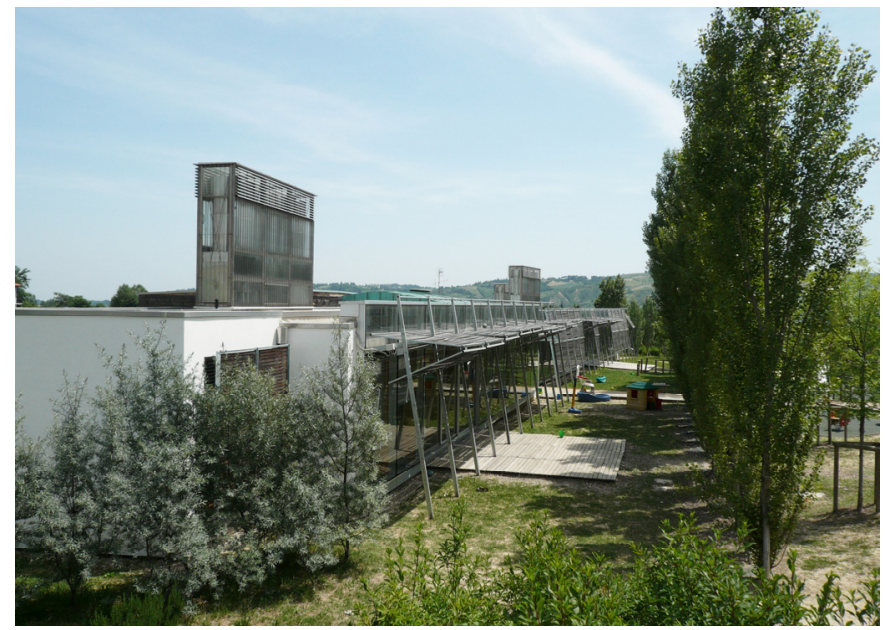

Figure 1: The integration of building and greenery, the attention paid to bioclimatic aspects improve the indoor and environmental quality. Protection with trees and shading with brise-soleil on the south glazed front. Nursery School in Ponticelli, Imola, 2001-2002, Arch.

A. Contavalli.

particularly interesting as case studies. The definition of design solutions and technical aspects for schools could represent an interesting reference applicable to other building types, according to different climatic conditions.

In relation to the age of users it is possible to distinguish different types of buildings: kindergartens, nursery, primary, secondary schools and comprehensive schools. The educational use is the common feature. They are articulated in different ways according to different age of users, educational models, the availability of spaces and resources.

International experiences of reference are programs as the CHPS Collaborative for High Performance Schools (U.S.A. program which defines guide-lines for design, construction and management of schools characterized by high quality performance); REDUCE - Energy Retrofit for Educational Building (European Program for performance and morphology upgrading of school buildings), BSF - Building Schools for Future (English program for refurbishment of secondary schools).

\section{Characteristics of sustainable schools}

Buildings for learning represent emblematic cases of experimentation of increasing levels of sustainability research. In these architectures the design and construction criteria related to site, orientation, and in general sustainable strategies are often adopted. 


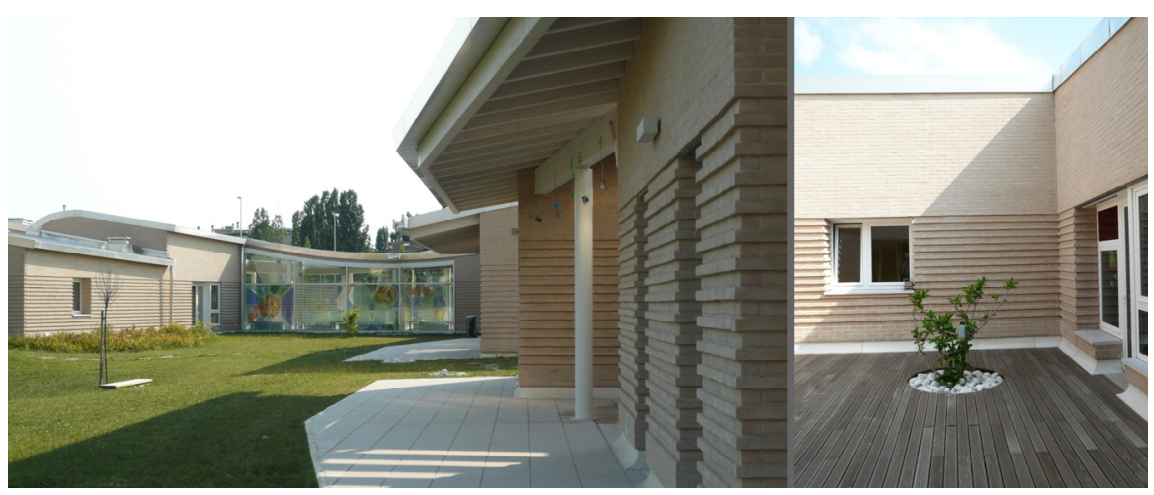

Figure 2: The articulation of volumes increases the dispersant surfaces but promotes natural ventilation and lighting inside. The system of open spaces includes a park and some patios. Lama Sud school in Ravenna, arch. G. De Carlo and Associates, 2008.

In the Mediterranean context, these buildings must have high performances in different seasons, thanks to a perfect integration with open spaces and ensuring low energy consumptions.

Schools can be considered as spaces which contribute actively to educate users for sustainability, responding to a double set of problems. The first is relate to criteria for functionality, concerning environmental implications, technical and morphological aspects, providing high hygro-thermal performances, natural and artificial lighting, using health materials. The second problems category concerns sustainability strategies that school buildings should communicate through their spaces, uses and performances. The aim is to promote the spread of environmental awareness among the users and citizens.

To pursue strategies of a sustainable approach in school buildings, characterized by an intense collective use, it is necessary to assess the problems in the first phase of design process in relation to strategies of urban planning and context analysis. Already urbanized areas, possibly abandoned, and equipped with adequate infrastructure, public and ecological transport system and pedestrian connections are to be preferred. It is important to maintain and enhance green system and permeability of soils, select materials with limited content of embodied energy and apply energy efficient solutions.

\section{Energy consumption in schools}

A significant parameter to be valued concerns the power consumption. Schools consume too much. The high energy consumption generally is due to low environmental quality, low insulation, use of no performed windows, presence of thermal bridges and obsolete equipment. These buildings are no comfortable and consume too much both in terms of economic impact and the environmental point of view. 
A recent survey of fifty schools in the Veneto Region in Italy, realized with a method of fast audit, has highlighted energy needs of $250-350 \mathrm{kWh} / \mathrm{m}^{2} \mathrm{a}$, with an average of $290 \mathrm{kWh} / \mathrm{m}^{2} \mathrm{a}$ which may correspond about to $82 \mathrm{kWh} / \mathrm{m}^{3} \mathrm{a}$. These data are significant: according to Italian regional classifications and regulations, these buildings would be classified in the worst energy efficiency class. A school classified A in Emilia Romagna, indeed, has an index of less than $8 \mathrm{kWh} / \mathrm{m}^{3} \mathrm{a}$ : that is to say that it consumes only $10 \%$ of the average requirements of the tested schools.

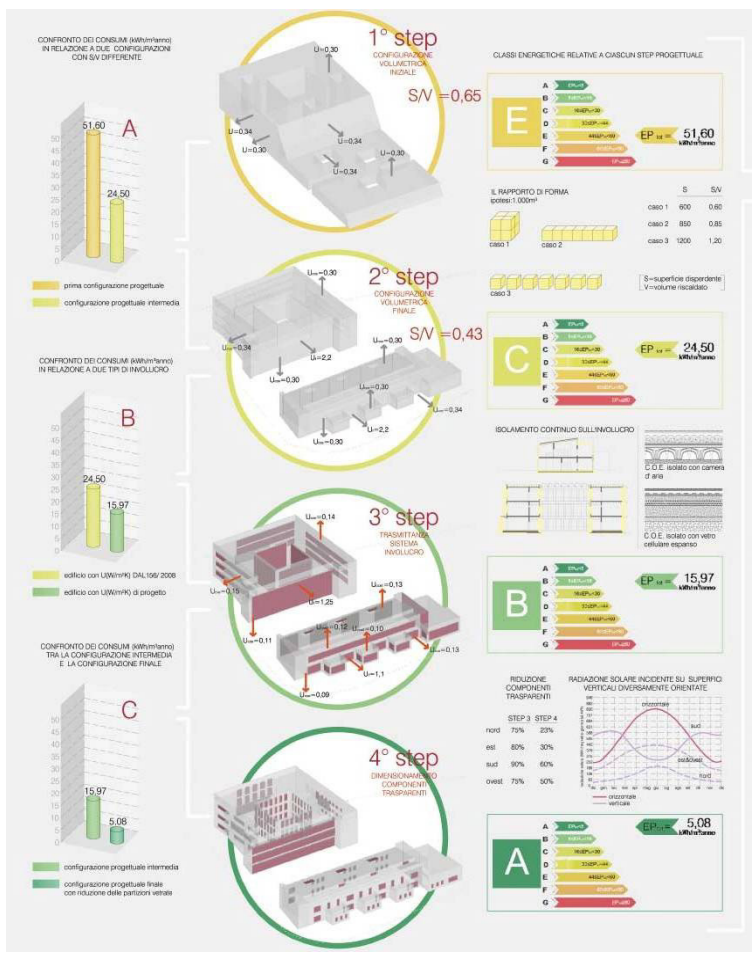

Figure 3: Comprehensive (primary and secondary) school design. Subsequent phases to meet energy performances aims, from $\mathrm{F}$ to A class with different configuration of volume and envelope. Eco-efficient architecture final workshop, coord. prof. Boeri, Faculty of Architecture, University of Bologna, AA 2008/09.

The aim consists of improving performance levels of buildings, providing better conditions of use and consuming less. The reduction of energy consumption and the possibility to meet needs of comfort represent a shared goal. The risk is that the low energy consumption is obtained, at least in part, losing environmental quality, in terms of good perception and functionality of spaces. 
On the other hand, it is necessary to promote sustainable design and construction strategies that combine high levels of energy efficiency, high performance standards and environmental indoor quality, through innovative strategies for integration of construction system and plants.

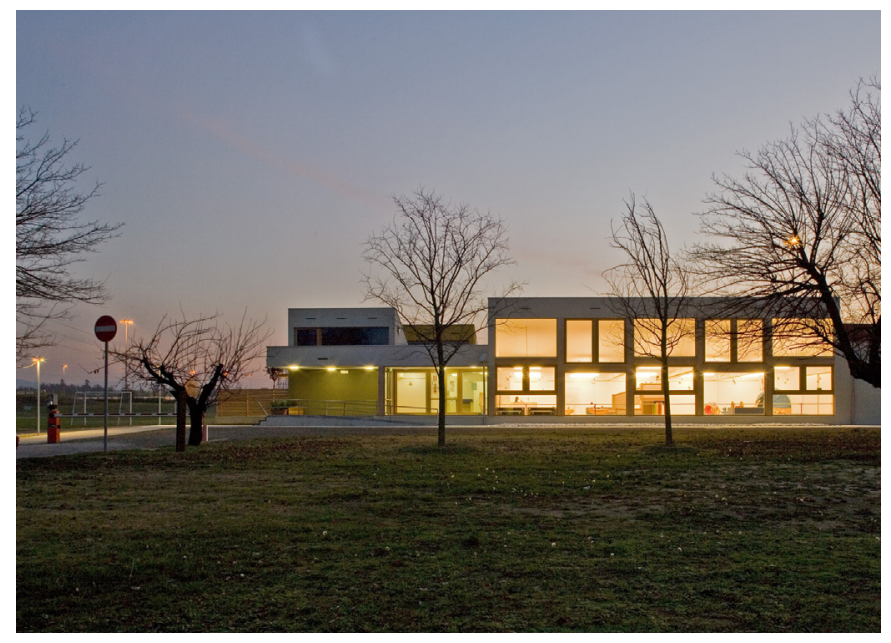

Figure 4: The design solutions for solar gains provide high indoor quality, increasing the natural lighting and visual relationship with the external context. Day nursery Balenido, Casalecchio di Reno (BO), 2007, Scagliarini-Tasca Studio, Bologna. Photo by Luca Capuano.

\section{Environmental sustainability evaluation}

The environmental sustainability assess of school buildings is a difficult operation, especially if it regards the entire life cycle analysis (phases of production, transport, installation, construction, management and demolition) and the environmental impact of site and building systems.

Multi-criteria evaluation systems can be applied, based on a compared analysis of significant parameters, to be eventually extended to the entire life cycle of the building.

In this case it is important to consider the energy consumption, a factor integrated with a complex series of other ones. The relative weight of various parameters can be adapted to different specific conditions of application. The national Protocol Itaca is one of these system.

LEED (Leadership in Energy and Environmental Design, an internationally recognized green building certification system, providing verification that a building was designed and built using strategies intended to improve performance in metrics such as energy savings, water efficiency, $\mathrm{CO}_{2}$ emissions reduction, improved indoor environmental quality) has developed a specific evaluation methodology for school buildings in USA and it has been wide spread in the world. It suggests a voluntary multi-criteria evaluation method of 


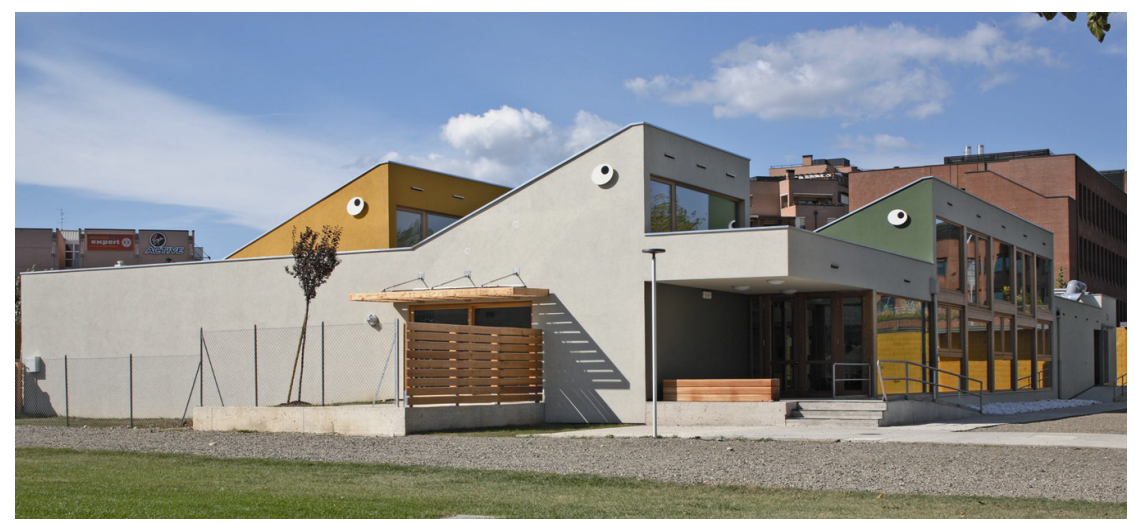

Figure 5: The integration with environment aims at microclimate control and exploitation of the potential relationship with surroundings. Day nursery Gaianido in Bologna, Tasca Studio.

environmental and energy quality for sustainable energy efficient buildings development, with the aim of improving the quality and minimize environmental impact.

The rating system is based on specific credits, assigned for each requirement concerning sustainable aspects. Points are distributed across major credit categories. Their sum determines the overall score of building and the level of certification is afforded. LEED certification is obtained after submitting an application documenting compliance with the requirements of the rating system as well as paying registration and certification fees.

This system considers lots of parameters of sustainability, from the adoption of renewable energy sources to the choice of appropriate materials, local, renewable, recycled, ecologic with low emission of organic substances. Based on the general value system, specific versions for particular types of buildings were developed, such as new construction, existing buildings, commercial spaces, residential buildings and schools.

The assessment of the sustainability of school buildings, primarily concerning the K-12 sector of primary and secondary schools (up to twelve years of schooling, corresponding to the age of seventeen or eighteen), is based on the specification of characteristics of these buildings, defined with a checklist articulate into thematic areas:

- Sustainable Sites

- Water Efficiency

- Energy and Atmosphere

- Materials and Resources

- Indoor Environmental Quality

- Innovation and Design

- Regional/local priorities. 
The sustainability assessment, applicable both to new schools and existing refurbished ones, is based on a checklist divided into different thematic areas. The first LEED Gold certification of a school in Italy dates back to 2009 and it was assigned to Technical Institute Floriani in Riva del Garda.

\section{Integration architecture - plants for environmental quality}

Sustainable school buildings are the result of a synthesis of architectural, technological and and engineering design. The volumetric articulation of spaces, the shape of the envelope, the adoption of bioclimatic strategies, the fixtures and fittings solutions in relation to energy requirements, the integration of renewable energy systems are the main factors to be considered.

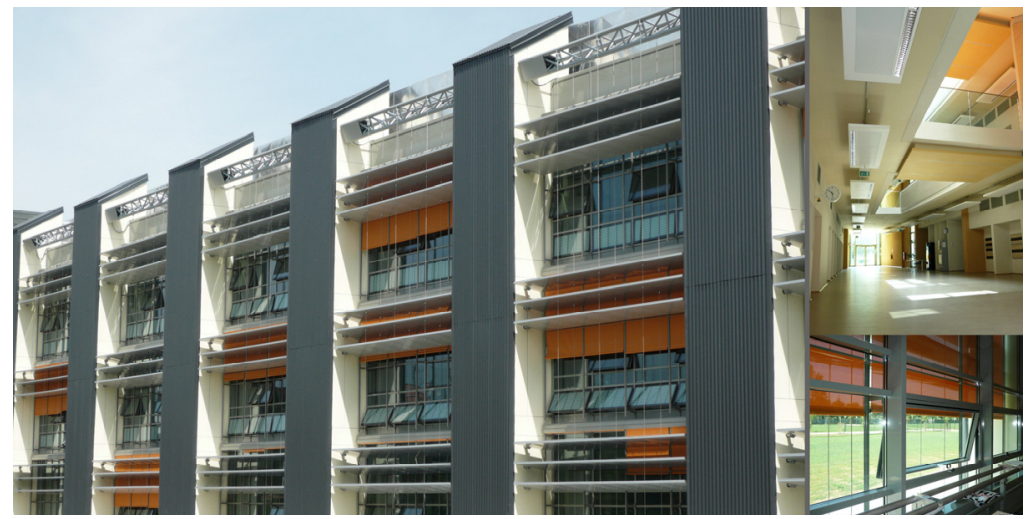

Figure 6: The south glazed facade is realized with transparent structural glasses $(\mathrm{Uw}=1.1 \mathrm{~W} / \mathrm{m} 2 \mathrm{~K})$, protected by mobile shields and curtains to limit eventual overheating. The vertical opaque elements allow the distribution of plants and are externally coated with solar panels for hot air production. Secondary school Orsini, Imola, 2009, Arch. A. Dal Fiume.

The reduction of energy needs of buildings allows the adoption of innovative systems for the air-conditioned.

The research of integration of architectural and technical aspects has to satisfy not only present needs: it is necessary to evaluate the potential development in the future, foreseeing and scheduling the following steps considering the environmental effects of each change.

To compensate the ecological footprint of construction process it is appropriate to provide integration of the specific building uses with activities opened to the surrounding community, extending the period of use and providing additional services for collective use.

The space and functions are differentiated in relation to the type of school and the age of the users. 


\section{Some case studies}

\subsection{Meridiana Nursery (Balenido), Casalecchio di Reno (BO).Scagliarini- Tasca Studio, Bologna, 2007}

The lot is located between an important road and a green area, near the services of the Meridian neighborhood.

The design is inspired by considerations related to the urban scale planning and the mobility system: the nursery school plays a synergistic relationship rule as a connecting element to the context. It is equipped with pedestrian access which serves the adjacent social center and sports facilities too.

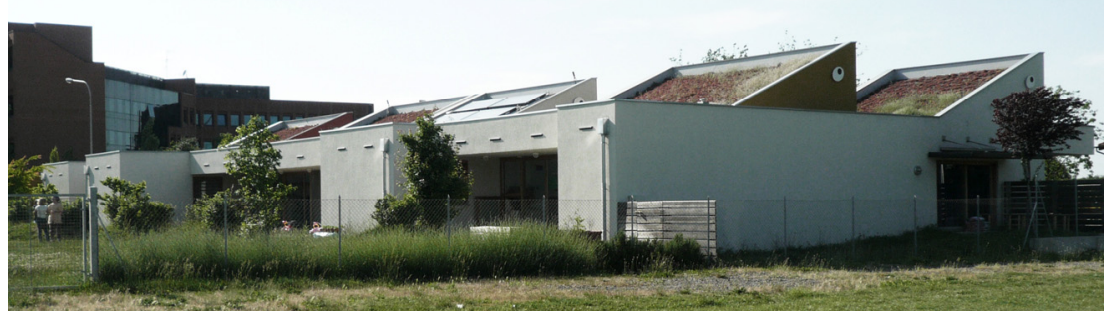

Figure 7: Green roof as element of environmental integration and microclimate control. Day nursery in Bologna, Tasca Studio.

\subsubsection{Materials and technologies}

The structural technologies, plants and materials applied in the building have two main aims: mental and physical wellbeing of users and the reduction of energy consumption, including embodied energy during the operating phase and eventual deconstruction/demolition phase.

Exposure, orientation and conformation of its spaces tend to create a relationship with the context and a bioclimatic balance.

The elevation structures are built with Wolf balloon frame system, applying frames in fir wood with transmittance between 0.18 to $0.22 \mathrm{~W} / \mathrm{m}^{2} \mathrm{~K}$. The external wall is $27.5 \mathrm{~cm}$ thick, with three types of insulation layers to ensure effective thermal inertia performance: panels of cork in the outer side, sheep wool and linen in the middle, panels of wood-magnesite with natural fiber gypsum plaster inside.

The finishing layer of the coat is realized with silicate plaster, with photocatalytic and colored treatment (it oxidizes organic and inorganic pollutants, transforming them into nitrates of sodium, calcium and carbon dioxide).

The windows provide high performances, too.

The roof was realized with a wooden structure as the walls, breathable waterproof sheath and a mantle of vegetation. It provides high insulation performances, drains rainwater, requires limited maintenance (due to the succulent plants and mosses) and contributes to the environmental contextualization of the building. 
The interior walls and ceilings are covered with natural fiber gypsum plaster. Low temperatures radiant panels are placed inside these structures; with this solution the walls do not require air conditioning terminals and may be freely used and furnished.

Particular attention was paid to the evaluation of toxicity of the materials: all surfaces are painted with natural paints and interior floors are finished with birch plywood treated with non-toxic and water paint.

\subsubsection{Fixtures and fittings and energy performances}

The school was designed with the purpose of obtaining the A plus certification in accordance with the methodology proposed by Clima House Agency.

The building is provided with a ventilation system with rate between 1.5 to $2.0 \mathrm{vol} / \mathrm{hr}$.

Solar panels are placed on the roof, covering an area of $10 \mathrm{~m}^{2}$, enough to provide hot water in summer and integrated heating in the winter.

The ventilation system is equipped with mechanized heat exchanger and a compressor heat pump to raise the energy values of the incoming air. A posttreatment battery contributes to contain the value of moisture inside during the summer period.

Other contributions to the air conditioning plants will be provided in summer with a refrigeration water system with coils embedded in the ground (geothermal system). In the winter season, the minimum integration required, especially during periods of cloudy weather, will be provided by local district heating system powered by the cogeneration plant next to the Meridiana neighborhood.

\subsection{Secondary school "L. Orsini", Imola. Arch. Andrea Dal Fiume (Public Works Sector, City of Imola), 2009}

The aim of this project is the achievement of high quality of design and construction and the attainment of optimal comfort indoor.

Built near the existing primary school, erected in the mid 80s, and sized according to local needs, the school building can hold 425 students. The new structure is closely coordinated with existing one, with common connective spaces and services (external areas, canteen, some laboratories, a library and the Direction Office) which have allowed a necessary functional reorganization of the general plant.

The design is based on bioclimatic criteria: the right orientation determines the plan organization of spaces and the functional distribution. The building is organized for the collection of solar radiation; the shell has opaque and transparent parts realized with different active technologies on the main front (the southern side) and a filter areas modulates the passage of air and light inside the building. The ventilation system integrates mechanized and natural passive cooling system.

The application of innovative technologies for indoor monitoring, climate control and energy production aims at integration between architecture and plants. Besides, the technologies applied aims to reduce the consumption of drinking water. 


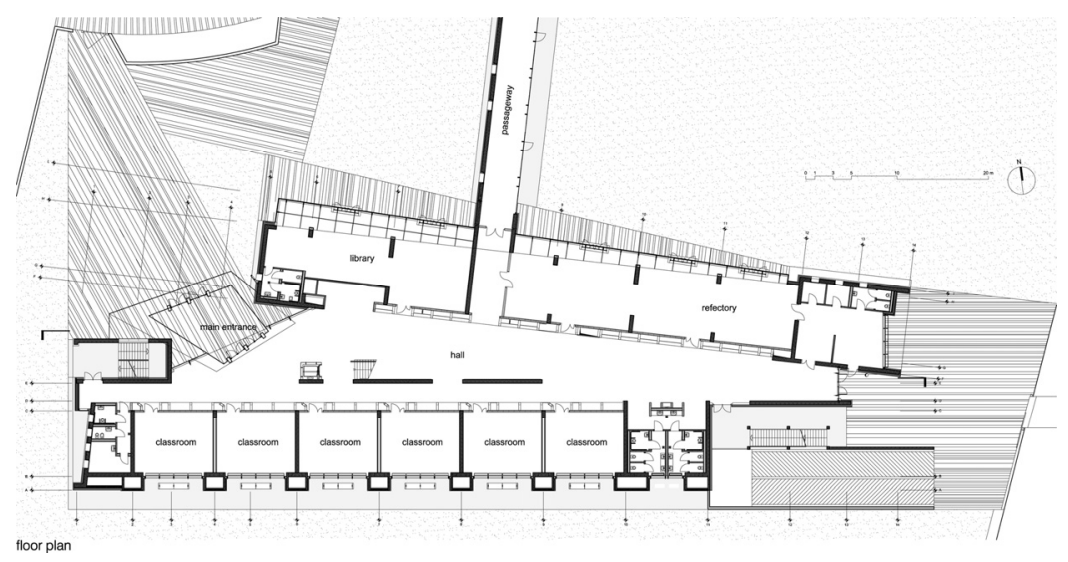

Figure 8: The layout of the school consists of two main parts. The southern building contains the teaching spaces; the northern one auxiliary activities (canteen, library, laboratories) and facilities. Secondary school Orsini, Imola.

The building has three floors. It is divided into two main parts, hardly rotated, connected to each other by a distribution area containing vertical connection structures.

Parts of the building facing south are used for teaching areas, in front of a public green area and hills. The glazed facade is characterized by a structural glass by Schuco with high thermal performance aluminum profile and lowemitting double glazing with a transmittance value of $1.1 \mathrm{~W} / \mathrm{m}^{2} \mathrm{~K}$.

Mobile brise-soleils and curtains allow the shadow of the facade and prevent eventual overheating during the summer.

The transparent portions of this facade are alternated with opaque vertical elements that allow the distribution of plants. They are externally covered with solar panels for production of hot air.

On the contrary, the northern facade is very closed and compact. Offices and workshops are located on the upper floors of the northern part of the building: the shell, mostly opaque with some modular windows, is coated with laminated plastic panels and zinc-titanium strips. The wall, realized with dry technology, with transmittance of $0.14 \mathrm{~W} / \mathrm{m}^{2} \mathrm{~K}$, has a frame in laminated wood, kenaf fiber panels of $22 \mathrm{~cm}$ thick, protected by breathable coating, plasterboard double wall in which pipes are concealed.

In this project the integration of plant components in the architecture plays an important role: the air-handling equipment, the ejector fan, solar collectors and photovoltaic panels are placed on the roof.

Particular attention has been put to acoustic comfort, ensuring insulation between adjacent rooms, facade insulation and reverberation time to compliance with regulatory (DPCM 05/12/1997 "Passive acoustic requirements of buildings") and to increase performances. 


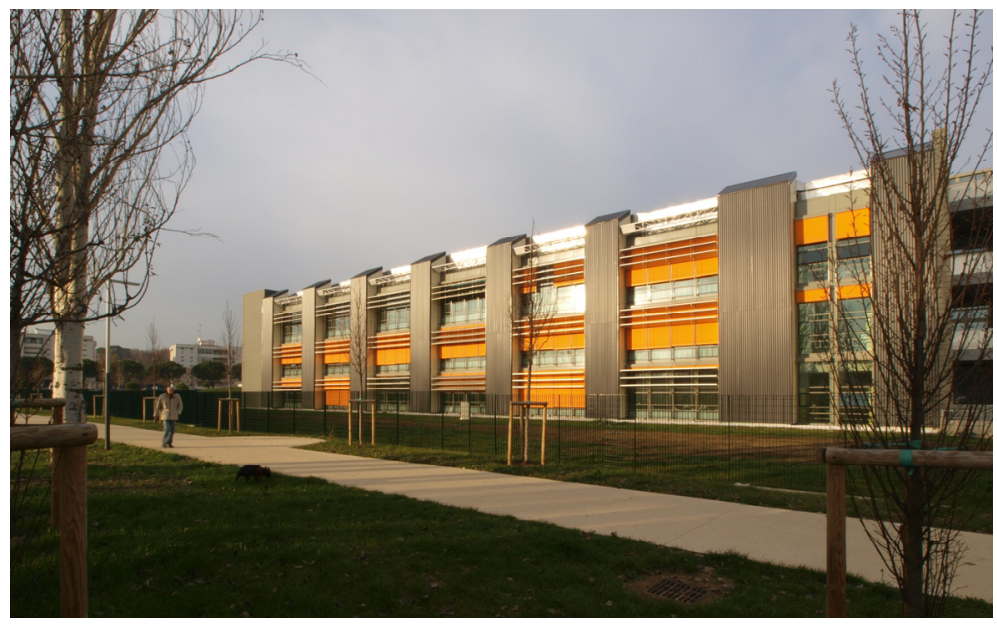

Figure 9: View of southern front facing on a green area and surrounding hills. The facade is characterized by opaque and glazed parts. Secondary school Orsini, Imola.

In particular, ceiling panels in MDF and a soundproof panel have also been used to improve the internal acoustic performances; tongue and groove paneling, perforated and milled, linked with a layer $2 \mathrm{~cm}$ thick of polyester fiber are placed on the walls.

Plant engineering system, adopted to minimize energy consumption of the building, has a strategic importance in the design:

- mechanical systems: solar air collectors $\left(\right.$ SolarWall ${ }^{\circledR}$ ) for pre-heating; solar collectors for water heating and integration of radiating under floor heating; cooling with absorption technology and solar cooling; geothermal system realized with underground pipes to preheat air and to cool the building; ventilated structural cooling system (RVS); separation of plant engineering systems to save energy consumption in relation to spaces uses; rainwater recovery and use for supplying toilet flush tank;

- electrical systems: high-efficiency lighting system with automatic timing device in relation to natural light, photo sensors to control lighting levels; presence detector with infrared receivers to control the switching of the lights, control systems of plants components and building passive systems, such as openings for natural ventilation and shading elements on the southern front; photovoltaic panels for partial meeting of the energy demand.

The high quality of the building and plant engineering integrated systems, characterized by effective integration of architecture and plants components through technical solutions, monitored during the design and construction phases, provides to obtain significant results.

The building has been certified Class A, according to KlimaHouse standards, with a requirement of $23 \mathrm{~kW} / \mathrm{m}^{2} \mathrm{a}$, less than half of regulations standards. 
The building is also heated and cooled using, as much as possible, natural and alternative energy sources such as solar and geothermal energy.

\section{Conclusion}

These experiences aim at integrating sustainability, spatial and perceptual quality with energy efficiency request in climates such as Italian and Mediterranean. The relationship with the outside spaces plays a significant role as it could contribute to improve indoor comfort and inside qualities.

International programs concerning the quality of school buildings are related with different national contexts; the quality is pursued paying particular attention to the specific context, defying and developing design criteria and construction methods, exploiting traditional input factors (such as orientation, shading, transparency and thermal inertia) in an innovative way.

\section{References}

[1] Boeri, A., Strategie sostenibili per l'edilizia scolastica. Efficienza energetica e qualità ambientale, in Integrare per costruire, SAIE 2010 - Cuore Mostra I Seminari, BolognaFiere, Be-ma, Milano, pp. 1-26, 2010.

[2] Boeri, A., "Criteri di progettazione ambientale - Tecnologie per edifici a basso consumo energetico", ISBN 978-88-89518-35-9, Editoriale Delfino, Milano 2007.

[3] Hertzberger, H., Space and Learning, 010 Publishers, Rotterdam, 2008.

[4] United States Green Building Council, Foundations of the Leadership in Energy and Environmental Design, Environmental Rating System, A Tool for Market Transformation, 2006, August. 